\title{
ON MORPHOGENESIS OF THE AGID PHOSPHATASE AGTIVITY; ITS SIGNIFIGANGE IN ADRENAL PIGMENTS FORMATION OF LANOLIN-TREATED RABBITS OR AGED RATS AND IN DEXTRAN STORAGE OF RAT LYMPH NODE MAGROPHAGES
}

\author{
Nobuo IHARA, Shuji FUNO AND Motohiro OGURA \\ Department of Pathology, Kansai Medical University, Fumizono-cho 1, \\ Moriguchi, Osaka 570
}

\begin{abstract}
The morphogenesis of ACPase activity was observed in the following experimental materials:

1) The parenchymal cells and macrophages of the adrenal cortex of cholesterol-treated rabbits.

2) The same cells of the adrenal cortex of aged rats.

3) The macrophages of the mesenteric lymph nodes of rats having received a large amount of macromolecular dextran.

In these experiments, (1) the increase or occurrence of activity as a function of biological significance was difficult to detect in cells displaying a degenerative process, notwithstanding their apparent histochemical stainability as "ceroid pigment", and (2) in the macrophages, under the present experimental conditions, the increase or occurrence of activity could be observed in more or less extensive areas of the cytoplasm, especially on the membrane system sharply demarcating these areas; the so-called residual bodies were seen to be produced there in groups concomitant with the appearance of their histochemical stainability as ceroid pigment.

This membrane system, judging by the evidence given by the plane ultrastructural pictures, seems to be intimately related to the smooth or rough ER system.
\end{abstract}

On the morphogenesis of acid phosphatase (ACPase) activity as a lysosomal marker, the theories proposed by different investigators have proved inconsistent.

The heterophagosome formation associated with phagocytosis or endocytosis is generally attributed to the fusion of phagosomes (heterophagosomes) with the primary lysosomes $(28,37)$. However, as to the origin of the ACPase in the phagosomes, which show complex contents including heterophagic vacuoles and/or degenerative cellular structures, and therefore cannot be clearly classified into an autoor heterophagic system, three theories have been proposed:

1) The route from the Golgi vesicles $(2,3,6,25,41)$ or the Golgi-associated endoplasmic reticulum (GERL) $(14,33,35), 2)$ the fusion with pre-existinglys osomes (2, $3,8,9,11,12,15,16,17)$, and 3$)$ the lysosomal wrapping mechanism $(29,30,38)$.

This third theory is considered to be the most favourable one, because it can explain the origin of both their limiting membranes and hydrolytic enzymes at the same time.

As to the origin of these limiting membranes, many investigators have proposed 
a number of extremely inconsistent theories $(3,8,14,16,30,33,35,41)$, among which, the theory of the wrapping mechanism $(2,7,13,16,18,20,24,34,41,44)$ with the endoplasmic reticulum (ER) is supported by the use of cytochemical marker enzymes $(2,16)$.

In the present study, the occurrence modes of the ACPase activity in the macrophages or parenchymal cells were examined in the following experimental materials:

1) The reticular zone of the adrenal cortex of cholesterol-treated rabbits and of aged rats.

2) The mesenteric lymph nodes of macromolecular dextran-treated rats.

Concerning the controversy as to origin, we were led to the conclusion that the ACPase activity might originate in the membrane system and be carried by it (through its own movement?) into the cytoplasmic area where residual or dense bodies take form and accumulate. This conclusion derives from our experimental observation that there is always an intimate connection between the ACPase activity and the membrane system possibly originating in the smooth or rough ER system, although we were unable to discover whether the role played by the Golgi apparatus is direct or indirect.

\section{MATERIALS AND METHODS}

\section{Experiment $I$}

The materials investigated consisted of the parenchymal cells and macrophages in the reticular zone of the adrenal cortex of cholesterol-treated albino rabbits: 12 experimentals and controls maintained on Purina Rabbit Chow (Oriental Yeast LTD.) and given free access to drinking water.

To the diets of the experimentals, $5 \%$ cholesterol was added for various periods ranging from 4.5 to 11 months, as shown in Table 1.

At sacrifice, each animal was given an intravenous overdose of Nembutal and exsanguinated. The adrenal glands were immediately removed to serve as experimental materials.

\section{Histochemical investigation}

In order to confirm the characteristic stainability or reactivity of the cells as "ceroid pigment" $(19,22,26,27,42)$, various histochemical tests were performed on the paraffin or frozen sections as shown in Table 2.

\section{Ultracytochemical demonstration of ACPase activity}

Frozen sections from tissues fixed in $2 \%$ glutaraldehyde solution for 2 hours at $0-4^{\circ} \mathrm{C}$ were incubated in a Gomori type incubation medium (21) for 10 minutes at $37^{\circ} \mathrm{C}$. After incubation, the sections were directly post-fixed in $1 \% \mathrm{OsO}_{4}$ solution buffered at $\mathrm{pH} 7.2$ with cacodilate and processed for electron microscopy. At the same time, a routine investigation of the ultrastructural morphology was performed on the tissue blocks.

\section{Experiment II.}

Aged rats, 9 to 29 months old, were used, as shown in Table 3. 
MORPHOGENESIS OF ACID PHOSPHATASE

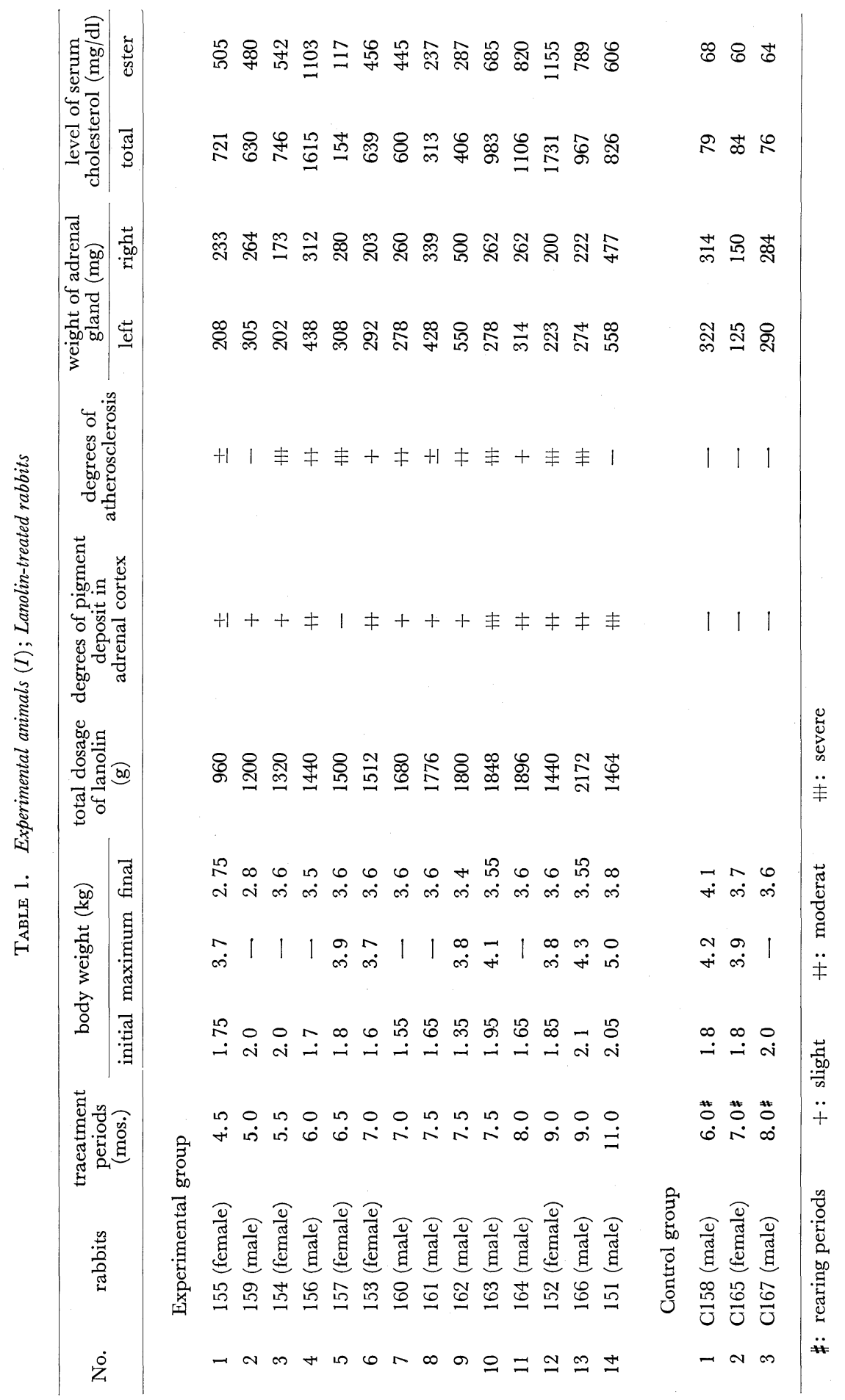


TABLE 2. Summary of histochemical properties of adrenal pigments occurring in lanolin-treated rabbits and in aged rats

\begin{tabular}{|c|c|}
\hline Staining tests & Findings \\
\hline Fluorescence & $\div \sim+\# \quad H \#$ \\
\hline Sudan black B & $H$ \\
\hline Sudan III & $H$ \\
\hline PAS & H \\
\hline Mallory's Aldehyde fuchsin & + \\
\hline Toluidin blue $(\mathrm{pH} 4.0)$ & + \\
\hline Acid fast fuchsin & + \\
\hline Nile blue sulphate (pH 3.0) & + \\
\hline Leucomalachite green & + \\
\hline NAHD-reaction for $\alpha$-acylamido-carboxyl radical & + \\
\hline Mercuri-affinity for $\mathrm{C}=\mathrm{C}$ bond & - \\
\hline Performic acid-schiff & + \\
\hline Indophenol-HCl (Peroxidase?) & \pm \\
\hline Acid phosphatase & $\div-H$ \\
\hline$\beta$-Glucuronidase & + \\
\hline
\end{tabular}

TABLE 3. Experimental animals (II); Aged rats

\begin{tabular}{|c|c|c|c|c|c|c|c|}
\hline \multirow{2}{*}{ No. } & \multirow{2}{*}{ rats } & \multicolumn{2}{|c|}{ age } & \multirow{2}{*}{$\begin{array}{c}\text { body weight at } \\
\text { sacrifice } \\
(\mathrm{g})\end{array}$} & \multicolumn{2}{|c|}{$\begin{array}{l}\text { weight of adrenal } \\
\text { gland }(\mathrm{mg})\end{array}$} & \multirow{2}{*}{$\begin{array}{l}\text { degree of pigment } \\
\text { deposit in } \\
\text { adrenal cortex }\end{array}$} \\
\hline & & year & mos. & & left & right & \\
\hline 1 & R-2148 (female) & & 8.5 & 220 & 24 & 26 & + \\
\hline 2 & R-2147 (male) & & 9.0 & 350 & 15 & 16 & + \\
\hline 3 & R-2152 (female) & 1 & 1.0 & 250 & 30 & 32 & $H$ \\
\hline 4 & R-2146 (female) & 1 & 4.5 & 220 & 33 & 32 & $H$ \\
\hline 5 & R-2153 (male) & 1 & 5.0 & 262 & 36 & 40 & H \\
\hline 6 & R-2151 (male) & 2 & 1.5 & 430 & 37 & 35 & H \\
\hline 7 & R-2145 (female) & 2 & 1.5 & 270 & 36 & 39 & $H$ \\
\hline 8 & R-2149 (male) & 2 & 2.0 & 390 & 32 & 30 & H \\
\hline 9 & $\mathrm{R}-2150$ (female) & 2 & 4.5 & 225 & 39 & 34 & H \\
\hline
\end{tabular}

Immediately after exsanguination, from the trunk arteries under deep ether anaesthesia, the adrenal glands were extirpated to serve for the cytochemical demonstration of ceroid pigment (40) or residual bodies and for the ultrastructural demonstration of ACPase activity, the processing being the same as that in Experiment I.

\section{Experiment III.}

The experimental materials consisted of the lymph nodes of three to seven month old male and female rats which had been treated with Dextran T500 (molecular 
weight: 500,000, Pharmacia Fine Chemicals). The pretreatment consisted of two intraperitoneal injections of the reagent given at a seven-day interval at a dosage of $4 \mathrm{gr}$ per $\mathrm{kg}$ body weight. At sacrifice, at 1, 2, 3, and 4 weeks after the final injection, the lymph nodes were immediately removed and processed in the same manner as in Experiments I and II.

To demonstrate dextran uptake in the macrophages, the tissue blocks were fixed in absolute alcohol and embedded in paraffin. The sections were subjected to the alcoholic periodic acid-Schiff test for the demonstration of dextran deposits in the phagosomes as described by Mowry et al. $(32,39)$.

\section{RESULTS}

\section{Experiment $I$.}

\section{7-ketosteroids and 17-hydroxycorticosteroids levels (Table 1) in 48 hours urine}

So much variation was observed at every stage that no definite tendency could be recognized in the experimentals as compared with the controls examined on the same days.

Changes of body weight, serum cholesterol levels, degrees of atherosclerosis, and adrenal pigment deposition (Table 1)

Significant decreases in body weight at the time of sacrifice were seen in Cases 155 and 159, and these were probably due mainly to abscess formations at the soles of the feet, having no significant effect on the adrenal pigmentation in these stages.

The degrees of the pigment deposition in the adrenal reticular zone was found to correspond fairly well with the periods of cholesterol treatment, but the degrees of atherosclerosis, which were divided into,$+ H$, and $H$ grades according to the extent of atheromatous plaque formation, did not always correspond with the treatment periods.

The weight of the adrenal gland was found to be significantly increased in four cases (over $400 \mathrm{mg}$ ), but there was no reliable correlation between these increases and the degrees of pigment deposition or the serum cholesterol levels.

\section{Cytological and cytochemical findings}

As seen in Fig. 1, many of the parenchymal cells in the reticular zone showed such extreme swelling and hypertrophy that their cell borders had become indistinct. Although these syncytial type cells displayed the staining character of a ceroid pigment, their autofluorescence was significantly weak, distinguishing them from the cortical cells of aged rats.

\section{Ultrastructural demonstration of ACPase activity}

Although the annular or granular deposition of the reactive substance in the form of typical lysosomes was observed in the cortical cells of the control adrenals (Fig. 2), the experimentals displayed hypertrophied syncytial cells, whose ultrastructures (especially those of membranes) were found significantly obscure with their irregularly shaped and possibly degenerative lipid vacuoles revealing little or no reactivity at the vacuolar circumstances (Fig. 3). 
In the sinusoidal macrophages of the reticular zone, typical lysosomes were found, some of which showed irregular shapes, such as that of a crooked dumb-bell form (Fig. 4). Besides, in those whose cytoplasms showed a storage of conglomerating or confluent vacuolar structures, a moderate reactivity was observed in the cytoplasmic area circumscribed by or sandwiched between such structures; that is, the probable heterophagosomes (Fig. 5). On the peripheral limiting membrane of those structures, somewhat weak reactivity could be observed.

\section{Experiment II.}

The cortical cells of the reticular and fascicular zones showed a deposition of reactive products mainly on the lysosomal limiting membranes and their peripheries (Fig. 6). It was interesting to note that the enzyme activity was found in the electronlucent zone surrounding the electron-dense bodies rather than within their limiting membranes.

In the sinusoidal macrophages, which contain several or many, grouped or scattered lysosomal bodies of various sizes and forms, though they were mostly spherical, frequently with vacuolar structure, the granular deposit of the activity appeared mainly in the peripheral zone or areas surrounding those bodies, sometimes diffusely in the extensive cytoplasmic areas (Figs. 7, 8 and 9).

\section{Experiment III.}

\section{Routine ultrastructural morphology}

At one to two weeks after injection, many macrophages were seen containing large amounts of vesicular phagosomes with electron-dense granules accumulating at the inner side of the limiting membranes, suggesting process of fusion with the electron-dense lysosomes.

At three to four weeks, these phagosomes showed an irregular or uneven increase in electron-density in addition to the progressive fusion process, and a definite tendency to form a large conglomeration. The conglomeration generally occupied a large area of the cytoplasm, contained some single, double, or multi-layered

FIG. 1. Using Mallory's aldehyde method for staining the basophilic property of the ceroid pigment, the hypertrophied syncytial type adreno-cortical cells in the reticular zone are stained positively. Cholesterol-treated rabbit. $\times 200$.

Figs. 2-5. Ultracytochemical ACPase in the parenchymal cells (Figs. 2 and 3) and macrophages (Figs. 4 and 5) in the reticular zone of the adrenal cortex. Cholesterol-treated rabbit. Fig. 2 shows an annular appearance of the activity in the control adreno-cortical cells of the reticular zone. $\times 12,000$. Fig. 3 shows only a very weak or indistinct activity on the circumference of the vacuoles with granular structure (arrow) in the parenchymal cells of syncytial type in the reticular zone. $\times 5,000$. Fig. 4 shows a typical activity of dumbbell-shaped lysosomes in the macrophages. $\times 10,000$. Fig. 5 shows a moderate activity in the cytoplasmic area enclosed by a group of vacuoles with granular structure. $\times 5,000$.

Figs. 6-9. Ultracytochemical ACPase in the parenchymal cells (Fig. 6) and macrophages (Fig. 7, 8, and 9) in the reticular zone of adrenal cortex. Aged rats. Fig. 6 shows a zonal occurrence of the activity in the periphery of the three grouped electron-dense bodies. $\times 5,000$. Fig. 7 shows a diffuse occurrence of the activity in the cytoplasmic area containing several electron-dense bodies. $\times 5,000$. Figs. 8 and 9 show an activity occurring in the peripheral zone of the grouping bodies with vacuolar structure. In the neighborhood, a macrophage can be seen showing an activity pattern similar to that shown in Fig. 7. Fig. 8: $\times 9,000$, Fig. 9: $\times 5,000$. 

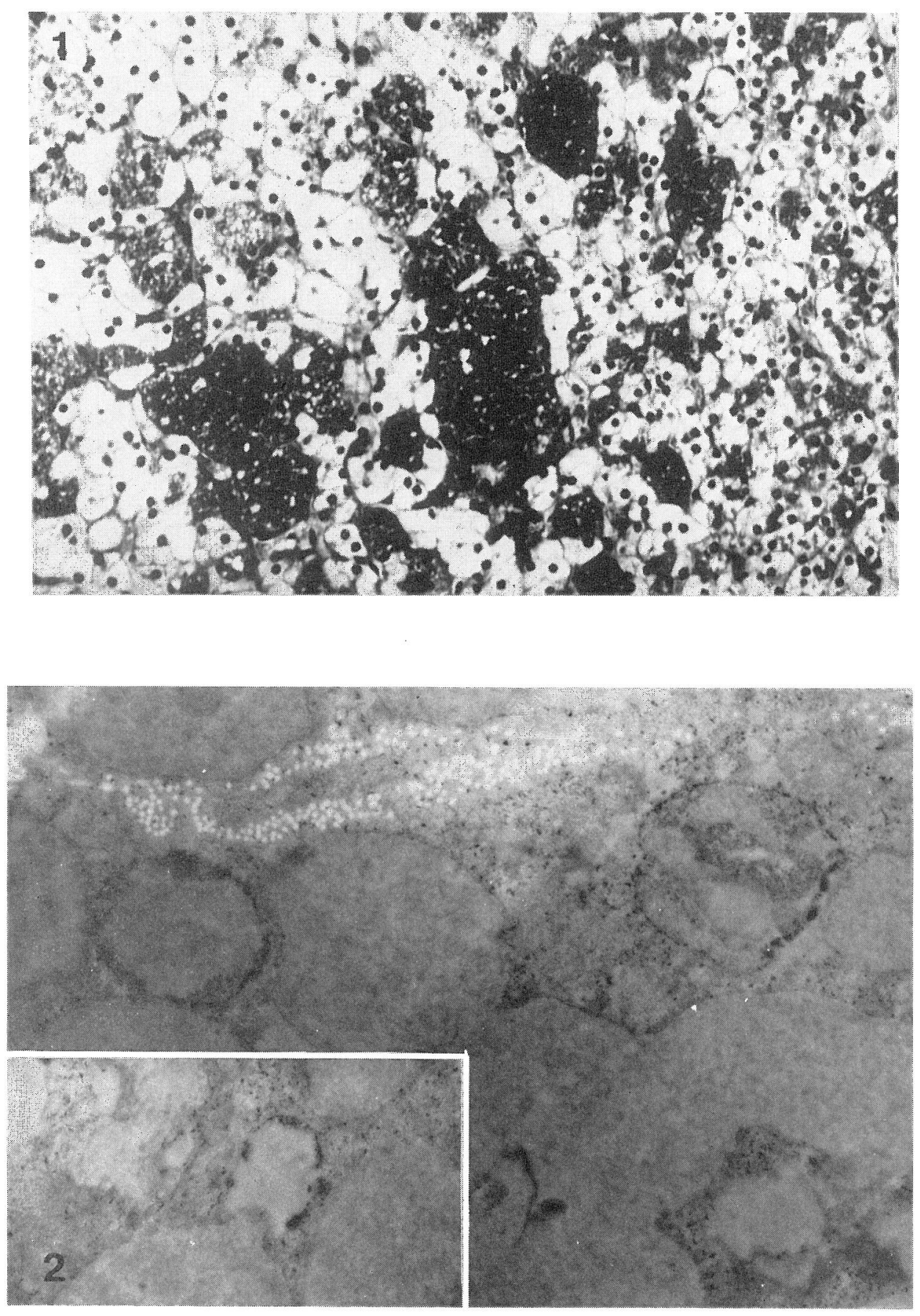

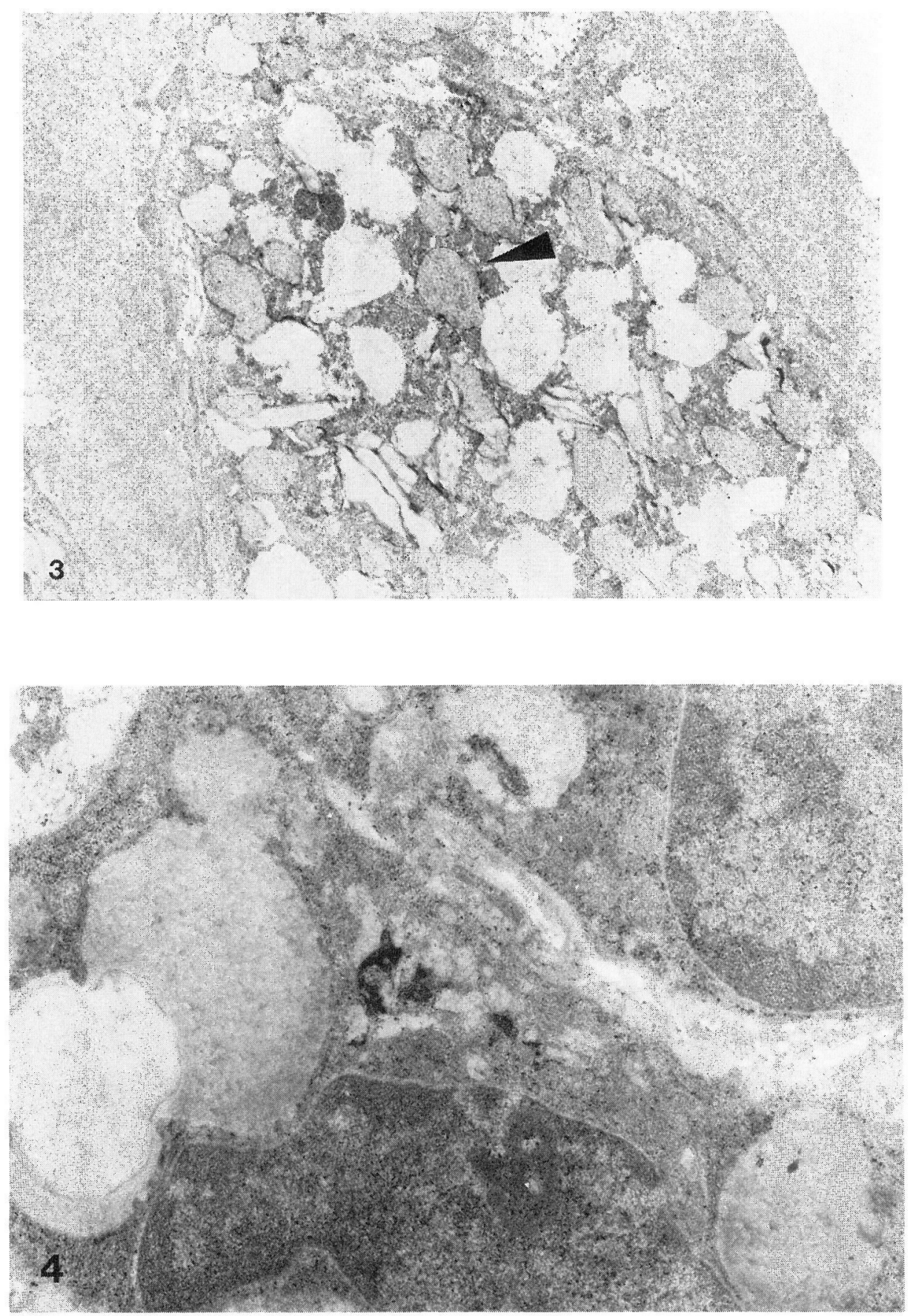

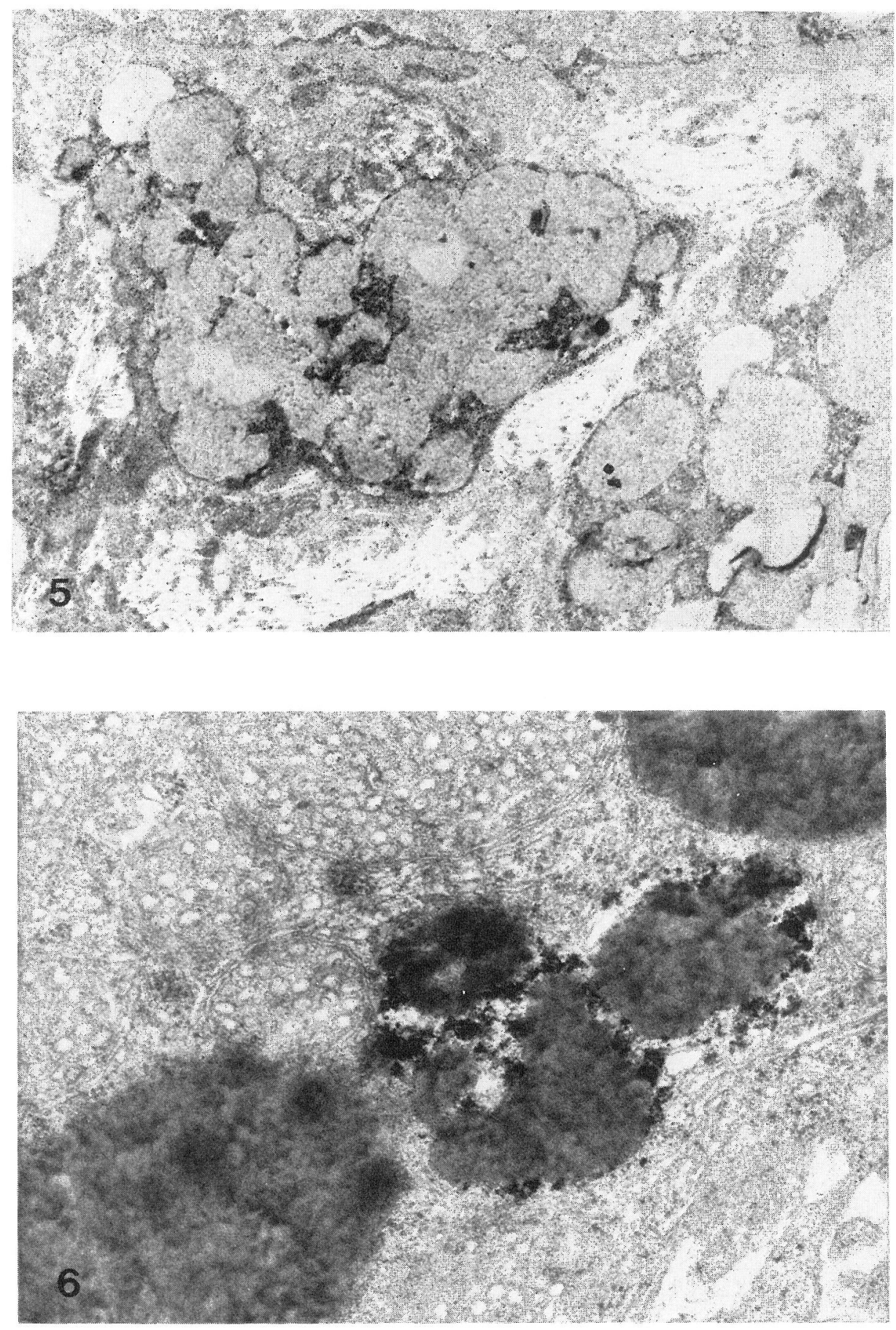

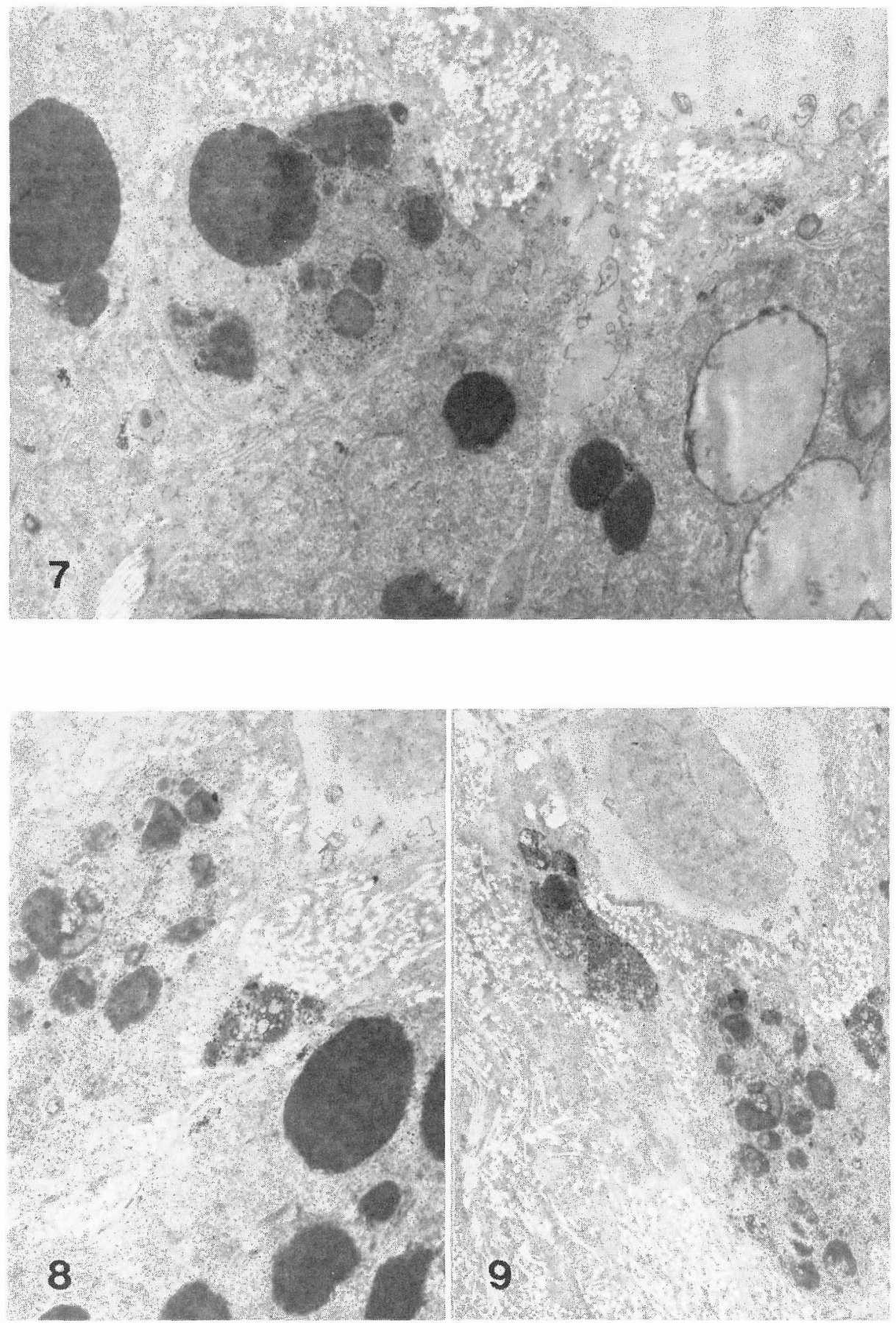


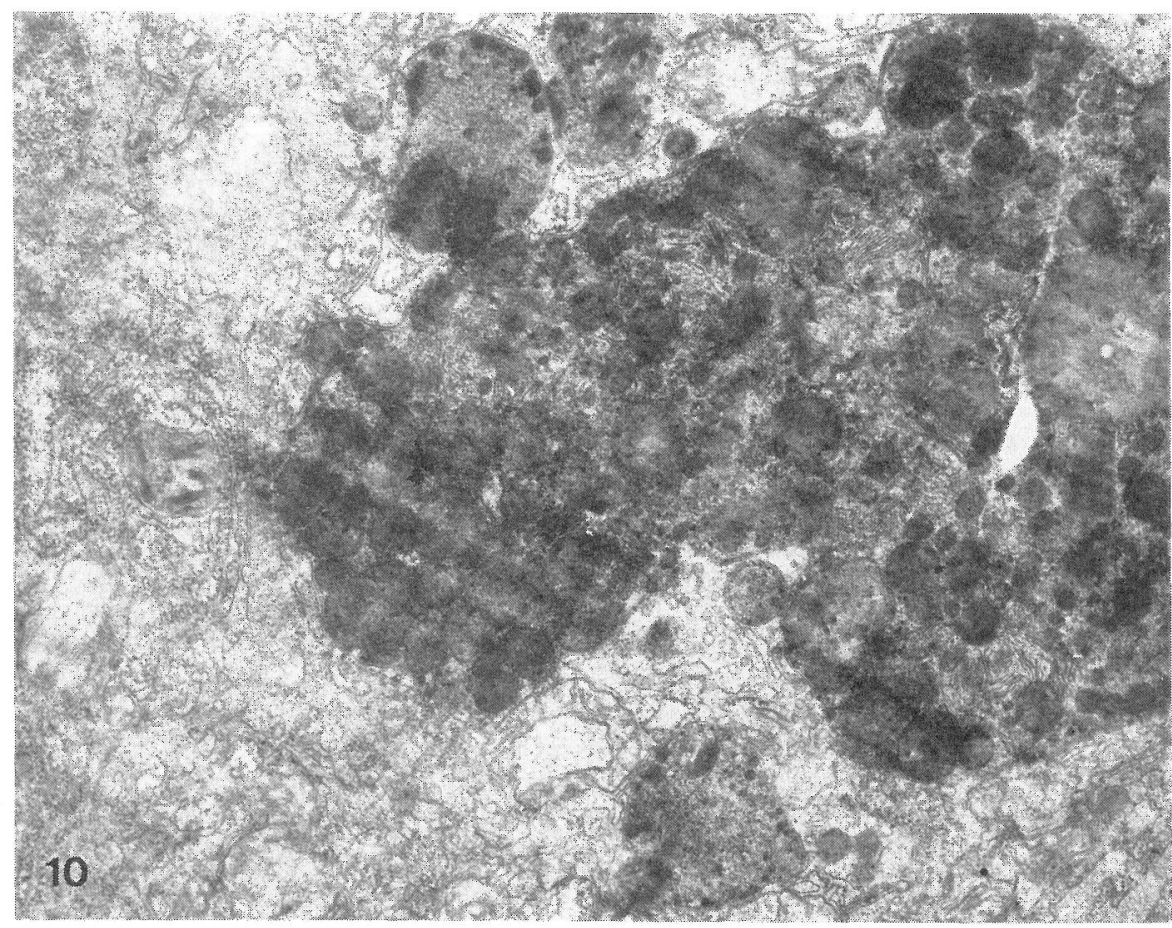

FIG. 10. The macrophages of the mesenteric lymph-node loaded with a large amount of electron-dense granules. Note the double membrane structure enveloping a group of these granules. Also, in the interior portion, a double or lamellar membrane structure can be seen. Dextran-treated rat. Ultrathin section double-stained with $\mathrm{U}$ and $\mathrm{Pb} . \quad \times 8,500$.

membrane or lamellar structures, and was encircled as a whole by a double membrane system with occasional interruptions here and there (Fig. 10).

\section{The ACPase activity findings}

In every stage, the occurrence of the activity showed a characteristic pattern occupying an extensive area of the cytoplasm, that is: (1) The activity appeared on the membrane system encircling a large number of phagosomes or dense bodies conglomerating in an extensive area of the cytoplasm (Figs. 12-a and -b). The membranes generally showed a double structure (Figs. 12-b and -c) whose intervals were not always uniform but were narrower than those of the smooth or rough ER. Many of the pictures, in so far as could be ascertained on the plane sections, suggested an intimate relationship between the membranes and the ramified rough ER system developing around the activity area (Fig. 13). Also in the inner space of the activity area, the enzyme activity was evident on the membrane structures, rather than in the internal portions of accumulating granular bodies which were recognized to be transforming into residual bodies within the large auto- or heterophagosome (Figs. $12-\mathrm{c}, 14$ and 15). 

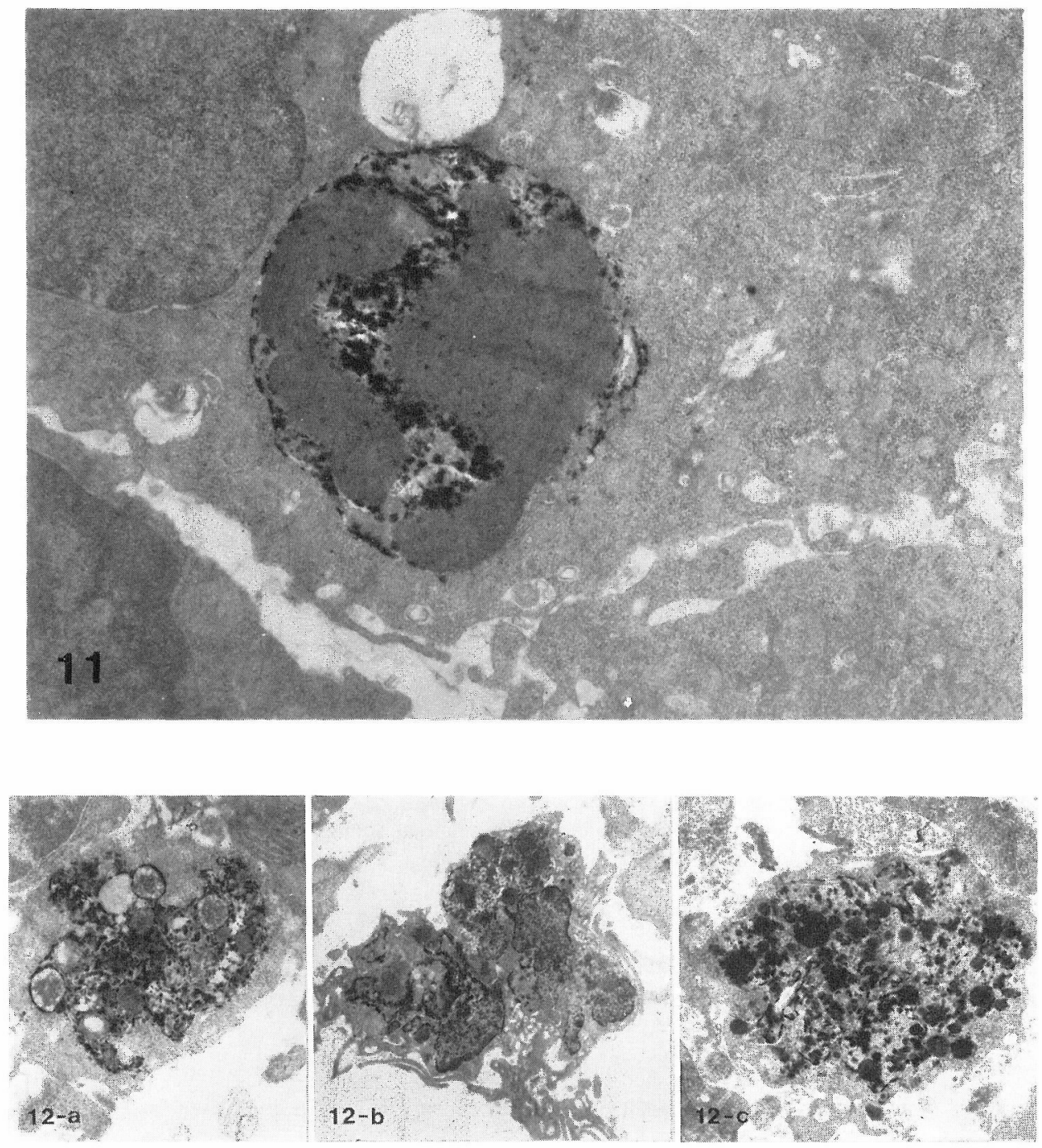

Figs. 11-15. Ultracytochemical AGPase activity in the lymph-node macrophages of dextran-treated rats. Fig. 11 shows a macrophage in which the enzyme activity occurs on the membrane structures (1) enveloping two dense bodies and (2) lying between them. Control rats. $\times 6,000$. Figs. 12-a, 12-b and 12-c show the ACPase occurrence in the extensive cytoplasmic areas, on the membrane system which (1) envelops groups of phagosomes or dense bodies, and (2) lies among them. $1 \mathrm{w}$. (Fig. 12-a: $\times 10,000$ ), 3 w. (Fig. 12-b: $\times 7,700$ ), 4 w. (Fig. 12-c: $\times 7,500)$ after dextran administration. Fig. 13. shows the intimate relationship between the activity area and developing, sometimes ramifying, rough ER system (arrow). 1 w. after dextran administration. $\times 6,000$. Fig. 14 shows an especially extensive area of activity occurrence. There is a local relationship with rough ER on this plane section. $3 \mathrm{w}$. after dextran administration. $\times 5,700$. Fig. 15 suggests that the ACPase activity is in the process of disappearing with an occurrence of a group of dense bodies (postlysosomes). 4 w. after dextran administration. $\times 7,700$. 

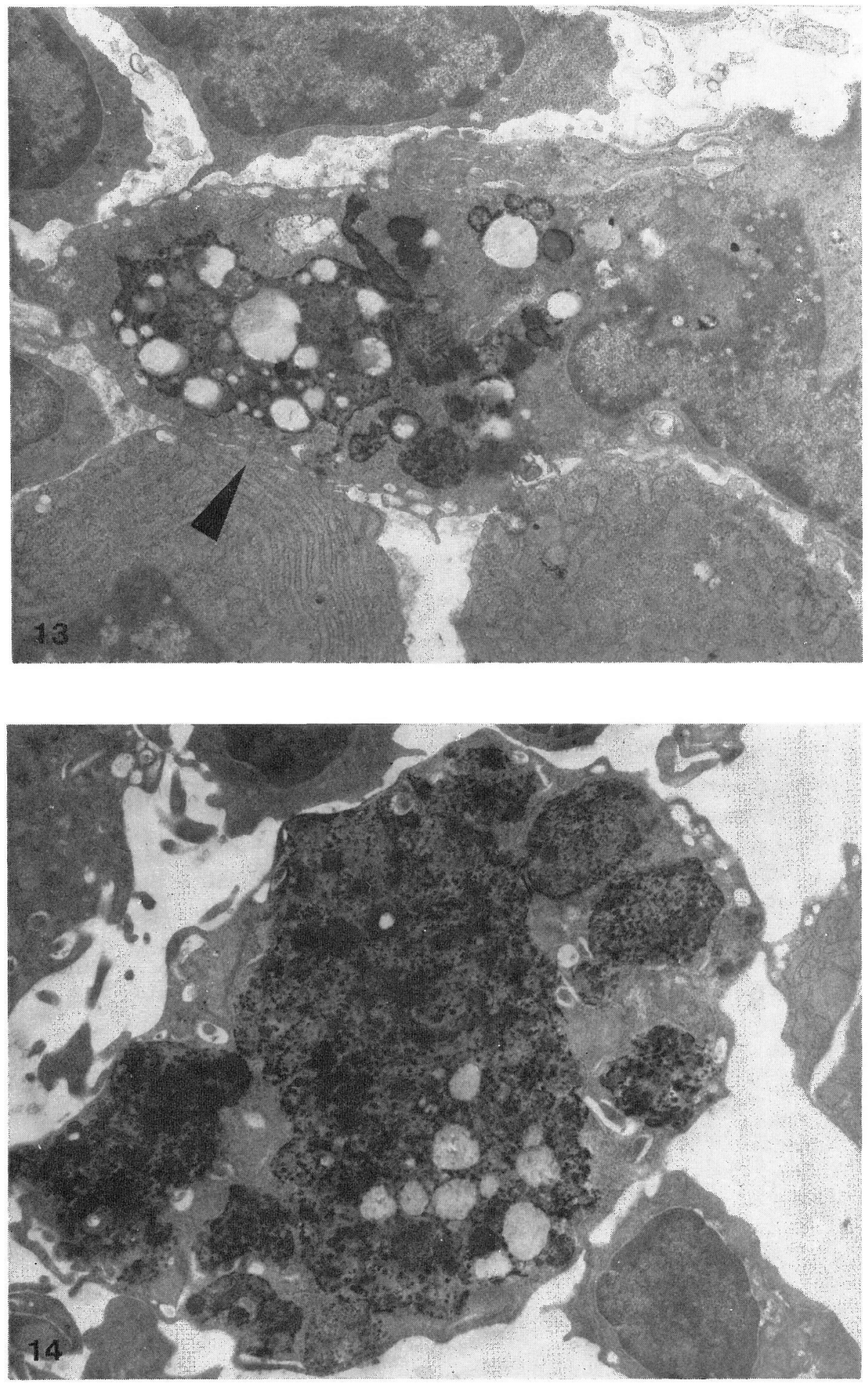


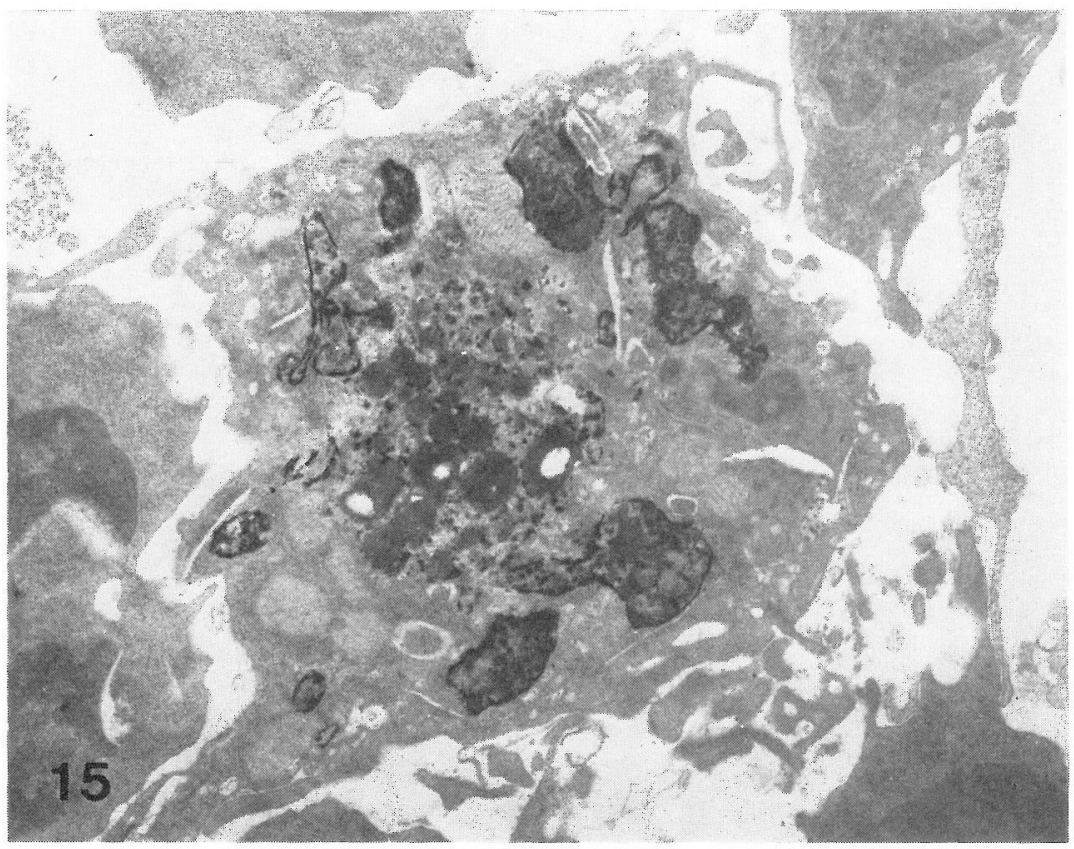

\section{DISGUSSION}

\section{The ACPase activity in the adrenal cortical cells of cholesterol-treated rabbits}

Suggesting the presence of the pigment or residual bodies formation process, the parenchymal cells of the syncytial cell type showed a characteristic stainability as ceroid pigment $(19,22,26,27,42)$ except for their weak autofluorescence. But almost no enzyme activity could be demonstrated, except for a localized and very weak reactivity on the limiting membrane of the degenerative lipid vacuoles.

This fact shows that a correlation between enzyme reactivity and cytochemical stainability is not always to be expected. In the routine morphological examination, the difficulty in discerning a distinct ultrastructural architecture, except for the presence of many irregular vacuoles, suggested the occurrence of a degenerative process on the total cell level rather than as a part of the physiological production of residual bodies, which would mean the activity of a digestive, segregative mechanism $(8,17,36)$ relating to the secretion or excretion process of steroid hormones. Thus, one possible speculation is that an outwardly apparent stainability as ceroid pigment might only indicate the occurrence of a degenerative process of the cytological structures as a matter of fact.

\section{The ACPase activity in macrophages of the adrenal cortex and of the lumph nodes}

It was noted that the enzyme activity occurred mainly in the more or less extensive areas occupied by phagosomes or residual bodies in the macrophages of the adrenal cortices of aged rats, as well as in those of the lumph nodes of dextrantreated rats, especially in those areas sharply demarcated by the reactive membranes from the residual cytoplasmic areas with little reactivity, in such a way as if to 
envelope the groups of "lysosome-like granules" widely and perfectly. In the granules themselves, however, only a relatively small activity could be detected.

As to physiological significance, this activity seems to be related to such partially or totally augumented functions of the macrophages as phagocytosis, digestion, or segregation $(8,10)$ in a process of the progressive adrenal pigment deposition in the aged rats, or as a result of intraperitoneal injections of large amounts of macromolecular dextran in the dextran-treated rats. The fact that activity increase as a total reactive area was relatively weak in the former rats, but relatively strong in the latter, may be in accordance with the animal conditions on the one hand, and with the process or the treatment dosage of foreign substances on the other.

As to ACPase increase after the administration of macromolecular substances (dextran, polyvinylpyrrolidon), similar results have been reported on both the light and electron microscopical levels $(31,43)$, but such a significant increase in extensive areas as reported in the present paper has not been reported elsewhere.

Mayahara (30) observed the occurrence of giant phagolysosomes in the subcutaneous macrophages after the administration of horseradish peroxidase. As a result of these observations, the theory of the lysosomal wrapping mechanism concerning the origin of autophagolysosomes (both the ACPase activity and the limiting membrane) was presented by Ogawa and Mayahara (29, 30, 38).

With respect to the present results, it is interesting to note that the AGPase activity becomes evident in the distinctly demarcated but extensive cytoplasmic areas of the macrophages, that this occurs mainly on the borderline membranes which envelops these areas, and that often the activity is to be seen on the single, double, or lamellar membrane system within these areas.

In conclusion, the activity findings suggest that the membrane system, especially the ER, the occurrence of the ACPase activity, and the formation of phagolysosomes may all be intimately related. Thus, the ACPase activity should be cytochemically recognized as "reactive areas" rather than as "reactive particles" when observed biochemically $(4,5)$, at least in the light of the present experimental results.

\section{REFERENCES}

1. Akazawa, Y.: On the urinary 17-ketosterois, 17-ketosteroid fractionation, 17-hydroxycorticosteroids and uropepsin of normal rabbits and experimental congenital diabetic rabbits. Folia Endocrinol. Jap. 35; 776, 1959 . (in Japanese).

2. Arstila, A. U. and Trump, B. F.: Studies on cellular autophagocytosis. The formation of autophagic vacuoles in the liver after glucagon administration. Am. J. Path. 53; 687, 1968.

3. Arstila, A. U., Jauregui, H. O., Chang, J. and Trump, B. F.: Studies on cellular autophagocytosis. Relationship between heterophagy and autophagy in Hela cells. Lab. Invest. 24; 162, 1971.

4. Baudhuin, P., Beaufay, H. and de Duve, C.: Combined biochemical and morphological study of particulate fractions from rat liver. Analysis of preparations enriched in lysosomes or in particles containing urate oxidase, D-amino acid oxidase, and catalase. J. Cell Biol. 26; 219, 1965.

5. Bowers, W. E. and de Duve, G.: Lysosomes in lymphoid tissue III. Influence of various treatments of the animals on the distribution of acid hydrlases. J. Cell Biol. 32; 349, 1964.

6. Brandes, D. and Bertini, F.: Role of Golgi apparatus in the formation of cytolysosomes. Exp. Cell Res. 35; 194, 1964. 
7. Cole, S., Matter, A. and Karnovsky, M. J.: Autophagic vacuoles in experimental atrophy. Exp. Mol. Pathol. 14; 158, 1971.

8. de Duve, C. and Wattiaux, R. R.: Functions of lysosomes. Ann. Rev. Physiol. 28; 435, 1966.

9. Deter, R. L., Baudhuin, P. and de Duve, C.: Participation of lysosomes in cellular autophagy induced in rat liver by glucagon. J. Cell Biol. 35; G11, 1967.

10. Deter, R. L.: Quantitative characterization of dense body, autophagic vacuole and acid phosphatase-bearing particle populations during the early phases of glucagon-induced autophagy in rat liver. J. Cell Biol. 49; 437, 1971.

11. Ericsson, J. L. E.: Transport and digestion of hemoglobin in the proximal tubule. I. Light microscopy and cytochemistry of acid phosphatase. Lab. Invest. 14; 1, 1965.

12. Ericsson, J. L. E.: Transport and digestion of hemoglobin in the proximal tubule. II. Electron microscopy. Lab. Invest. 14; 16, 1965.

13. Ericsson, J. L. E., Trump, B. F. and Weibel, J.: Electron microscopic studies of the proximal tubule of the rat kidney. II. Cytosegresomes and cytosomes: Their relationship to each other and to the lysosome concept. Lab. Invest. 14; 1341, 1965.

14. Ericsson, J. L. E. and Glinsmann, W. H.: Observations on the subcellular organization of hepatic parenchymal cells. I. Golgi apparatus, cytosomes, and cytosegresomes in normal cells. Lab. Invest. 15; 750, 1966.

15. Ericsson, J. L. E.: Mechanism of cellular autophagy. In Lysosomes in Biology and Pathology, ed. by J. T. Dingle and H. B. Fell, North-Holland Pub. Co., Amsterdam, Vol. 2, 1969, p. 346.

16. Ericsson, J. L. E.: Studies on induced cellular autophagy. II. Characterization of the membranes bordering autophagosomes in parenchymal liver cells. Exp. Cell Res. 56; 393, 1969.

17. Farquhar, M. G.: Lysosomes function in regulating secretion: Disposal of secretory granules in cells of the anterior pituitary gland. In Lysosomes in Biology and Pathology, Vol. 2, ed. by J. T. Dingle and H. B. Fell, North-Holland Pub. Co., Amsterdam, 1969, p. 462.

18. Fedorko, M. E., Hirsch, J. G. and Cohn, Z. A.: Autophagic vacuoles produced in vitro. II. Studies on the mechanism of formation of autophagic vacuoles produced by chloroquine. $J$. Cell Biol. 39; 392, 1956.

19. Gedigk, P. and Bontke, E.: Über den Nachweis von hydrolytischen Enzymen in Lipopigmenten. Zellforsch. 44; 495, 1956.

20. Glinsmann, W. H. and Ericsson, J. L. E.: Observations on the subcellular Organization of hepatic parenchymal cells. II. Evolution of reversible alterations induced by hypoxia. Lab. Invest. 15; 762, 1966.

21. Gomori, G.: "Microscopic Histochemistry. Principles and Practice". Univ. Chicago Press, Chicago, 1952.

22. Hartroft, W. S. and Porta, E. A.: Ceroid. Am. J. Med. Sci. 250; 324, 1965.

23. Helminen, H. J. and Ericsson, J. L. E.: Studies on mammary gland involution. II. Ultrastructural evidence for auto- and heterophagocytosis. J. Ultrastruct. Res. 25; 214, 1968.

24. Holtzman, E., Novikoff, A. B. and Villaverde, H.: Lysosomes and GERL in normal and chromatolytic neurons of the rat ganglion nodosum. J. Cell Biol. 33; 419, 1967.

25. Locke, M. and Collins, J. V.: The structure and formation of protein granules in the fat body of an insect. J. Cell Biol. 26; 857, 1965.

26. Maeda, R.: The histochemistry of ceroid and ceroid like pigment (special lecture). Proc. Jap. Histochem. Ass., the 6th annual general meeting, 2-7, 1965.

27. Maeda, R.: The origin and characteristics of ceroid. Acta path. Jap. 17; 439, 1967.

28. Mayahara, H. and Ogawa, K.: Function of coated vesicles during protein uptake by the mouse subcutaneous histiocytes. Symposia Cell Biol. 21; 293, 1970 (in Japanese).

29. Mayahara, H.: Ultracytochemistry of mouse subcutaneous histiocytes. 1. Processes of the horseradish peroxidase uptake. J. Kansai Med. Sch. 24 (suppl.); 74, 1972.

30. Mayahara, H.: Ultracytochemistry of mouse subcutaneous histiocytes 2. Mechanism of autophagolysosome formation. J. Kansai Med. Sch. 24 (suppl.); 98, 1972. 
31. Meijer, A. E. F. H. and Willighagen, R. G. J.: Increased activity of acid phosphatase and $\beta$-glucuronidase in the liver and spleen of mice after intraperitoneal administration of various macromolecular substances. Biochemical Pharmacology. 8; 389, 1961.

32. Mowry, R. W., Longley, J. B. and Millican, R. C.: Histochemical demonstration of intravenously injected dextran in kidney and liver of the mouse. J. Lab. Cli. Med. 39; 211, 1952.

33. Novikoff, A. B., Essner, E. and Quintana, N.: Golgi apparatus and lysosomes. Fed. Proc. 23; 1010, 1964.

34. Novikoff, A. B. and Shin, W.: The endoplasmic reticulum in the Golgi zone and its relations to microbodies, Golgi apparatus and autophagic vacuoles in rat liver cells. J. Microscopie 3; 187, 1964.

35. Novikoff, P. M., Novikoff, A. B., Quintana, N. and Hauw, J.: Golgi apparatus, GERL, and lysosomes of neurons in rat dorsal root ganglia studied by thick section and thin section cytochemistry. J. Cell Biol. 50; 859, 1971.

36. Ogawa, K.: Intracellular membrane system and acid phosphatase. Symposia of the Society for Cellular Chemistry. 13; 41, 1963 (in Japanese).

37. Ogawa, K., Saito, T. and Mayahara, H.: Ultrastructure of lysosome. The Cell 2; 2, 1970 (in Japanese).

38. Ogawa, K., Mayahara, H. and Ago, Y.: Structure and function of lysosome. Metabolism 9; 242, 1972 (in Japanese).

39. Osawa, K.: Formation of Ceroid-like pigment by infusion of dextran (a histochemical and electron microscopical study). J. Kansai Med. Univ. 28; 556, 1976 (in Japanese).

40. Samorajski, T. and Ordy, J. M.: The histochemistry and ultrastructure of lipid pigment in the adrenal glands of aging mice. J. Gerontol. 22; 253, 1967.

41. Swift, H. and Hruban, Z.: Focal degradation as a biological process. Fed. Proc. 23; 1026, 1964.

42. Takada, R.: Histochemical study on the ceroid pigment. Tr. Soc. Path. Jap. 49; 1035, 1960 (in Japanese).

43. Thivolet, J., Leung, T.K., Duverne, J., Leung, J. and Volle, H.: Ultrastructural morphology and histochemistry (acid phosphatase) of the cutaneous infiltration by polyvinylpyrrolidone. Br. J. Derm. 83; 661, 1970.

44. Trump, B. F. and Bulger, R. E.: Studies of cellular injury in isolated flounder tubules. I. Correlation between morphology and function of control tubules and observations of autophagocytosis and mechanical cell damage. Lab. Invest. 16; 453, 1967. 